\title{
Patients' Perception on Benefits of Medications for treating diabetic Peripheral Neuropathic Pain
}

\author{
Article by Ahmed M.A. Yousif ${ }^{1}$, Tag Eldin O. Sokrab ${ }^{2}$, Hassan Tawfik ${ }^{3}$, IsamEldin \\ Abdelbagi ${ }^{4}$, Samah A. Mazin ${ }^{5}$, Reem Sharaf ${ }^{6}$, Reem S. Ebid ${ }^{7}$, Ahmed Salem ${ }^{8}$, Jyothi \\ Gopimenon $^{9}$, Rowayda Hadi ${ }^{10}$, Amr Rezk ${ }^{11}$, Samah Attia ${ }^{12}$, Marwa Khakli1 ${ }^{13}$, Ahmed \\ Elzarka $^{14}$, Eyas Shehadeh ${ }^{15}$, Mohamed Salah ${ }^{16}$, Mudather Jaber ${ }^{17}$ \\ ${ }^{1}$ Pharmacy Supervisor. PHCC /MSc in Clinical Pharmacy \\ ${ }^{2}$ Senior Cons. of Neurology /HGH (Hamad General Hospital) \\ ${ }^{3}$ Consultant of family medicine /PHCC (Primary Health care Corporation) \\ ${ }^{4}$ Senior Consultant of family medicine/PHCC \\ 5, 7, 12, 15, 16, 17 Senior Pharmacist/PHCC \\ 6, 8,9,10,11,13,14 Pharmacist/PHCC \\ E-mail: ayousif50@gmail.com
}

\begin{abstract}
Background: About 16\% of the adult Qataris at ages of 20 to 79 were diabetic. The prevalence of peripheral diabetic neuropathy in Arabic ranged between 38-94\% in diabetic. Medications in studied were Amitriptyline, Carbamazepine, Celecoxib, Diclofenac, Duloxetine, Fluoxetine, Gabapentin, Imipramine, Meloxicam, Paracetamol and pregabalin.

The specific objective; how the DPNP patients would perceive the benefits of medications Secondary objectives; which medication(s) perceived to restore a patient's quality of life. In addition, which medications could realize a 50\% benefits for releasing DPNP.

Setting: participants selected randomly, when attended their routine appointments in six health centers under in Qatar.

Sample size: 646 DPNP participants

Inclusion criteria: Diabetic from 18 years and above, taking medications to treat DPNP for duration of at least three weeks.

Exclusion criteria: Patients taking same medications for other ailments, diabetic less than 18 years old, and those with difficulty in communication. Results: Participants showed abilities to perceive the benefits of their medications, and their impact on some domains of quality of life. Gabapentin perceived by average percent of $70.70 \%$ to be beneficial in the above mentioned domains. Imipramine perceived by $24 \%$ beneficial. Fluoxetine not completely perceived as beneficial. Nonsteroidal anti-inflammatory drugs studied perceived to be less than $50 \%$ beneficial. Conclusion: Patient's perception on benefits of medications may be of high importance factor in medication selection. Anticonvulsants perceived to be more beneficial than other medications group. Recommendations: Consider patient's preferences in selection medications.
\end{abstract}

Keywords: Patients' perception, diabetic peripheral neuropathy medications.

\section{Introduction}

Diabetic peripheral neuropathy DPN is a common complication of diabetes mellitus. It usually affects the legs and feet. It may cause an injury of sensation or pain. DPNP often begins gradually and the symptoms may be a burning sensation or numbness that starts in the toes and /or the balls of the feet and spreads upwards. Sometimes, the skin may become so sensitive that the slightest touch is painful. Symptoms may also include unexpected severe pain, and electric shock-type pains or intense aching. At times, the DPNP may be just noticeable and at other times, it may be almost intolerable. DPNP commonly deteriorates at night. This can cause or worsen sleep disorders.

In some people, DPNP may have an impact on an individual's quality of life (Davies M, et al. 2006). DPNP may interfere with a patient's mood, sleep, energy, mobility, work, social activities and their enjoyment of life (Galer BS, et al, 2000).DPN occurs in 30 to 50 percent of patients with the diabetes, Barrett AM, et al .2007) 
Controlling hyperglycemia, which may highly worsen pain, is essential step in relieving the DPNP (Lee JH, et al 1990)

In June 2013 Action on Diabetes (AOD), a joint initiative by the Supreme Council of Health in State of Qatar and other organizations, they completed a public screening campaigns that have been carried across malls in Doha, capital of Qatar. The results of these screening campaigns come as a statement from (AOD); that about 16\% of the adult Qatari population between the age of 20 and 79 suffers from diabetes. Studies in the Arab world show prevalence of neuropathy ranging between $37-94 \%$ in diabetic foot cases, (Almoutaz Alkhier et al. 2011)

Bener A, et al (2009) has reported that ;the overall prevalence of diabetes mellitus (DM) among adult Qatari population found to as high as (16.7\%) with diagnosed DM (10.7\%) and newly diagnosed DM was $(5.9 \%)$.

The generic medications that are used to treat DPNP include tricyclic antidepressants like amitriptyline, imipramine (Saarto T and Wiffen PJ. 2007).Wernicke JF et al.( 2006) has reported that the newer anticonvulsants like pregabalin, gabapentin and serotonin-norepinephrine reuptake inhibitors e.g. duloxetine they can be used for treating DPNP.

Some other medications are prescribed in PHCC in Qatar include carbamazepine and some nonsteroidal anti-inflammatory like diclofenac, celecoxib, meloxicam, paracetamol. PHCC does not permit use the following medications of opiate, venlafaxine, lidocaine batches and capsaicin cream in the health center for treating the DPNP. Rationale or justification of the current research is referred to in general shortage of studies or research that have observed patients' perceptions on the benefits of medications that they took to treat their ailments.

Depending on internet search has not shown any study, particularly carried in the State of Qatar about the patients' perceptions of the benefits of the medications, but the current study has been the first study about the patients' perception of the benefits of medications to treat DPNP. In accession to that, higher prevalence of diabetes mellitus among adult Qatari population was high (16.7\%), as good as the higher occurrence of diabetic peripheral neuropathy pain at a rate of 30 to 50 percent of patients with diabetes mellitus.

The specific aims of the current study are to know how diabetic patients, with diabetic peripheral neuropathic pain perceive the benefits of medicine used to handle it. The secondary aim is; which medication can restore patient quality of liveliness. Consequently, which medication realizes a $50 \%$ of the benefits and release diabetic peripheral neuropathic pain in five domains that add up in the selfassessment questionnaire used in the present work.

\section{Materials and methods}

\section{Setting}

Data samples collected from six randomly selected health centers. Two health centers from each region; from Northern region health centers of Al Gharafa and Madinat Khalifa, from central region health centers of Umm Ghuwailina and West Bay from, and health centers of Abu Nakhla and Mesaimeer from Western Region. The study carried from 30 April 2015 to 30 April 2016.

\section{Study design}

It was an observational and qualitative study. The setting was a random selection of diabetic patients on medication(s) to treat DPNP, and they attended their routine appointments in six health centers.

\section{Criteria of inclusion}

- Applied to both male and female who were at the age of 18 years or older.

- Participants who were taking medications to treat DPNP for a duration of at least three weeks at the time of collecting data and patient's participation.

\section{Exclusion criteria}

- Patients who were taking same medications for treating other ailments, epilepsy.

- Patients who was less than 18 years old.

- Patients have disability that prevents them from natural communication. 


\section{Background information to the sample design}

The targeted population for this present study is all citizens and expatriates in State of Qatar, who receive medical care and medications treatment for diabetic peripheral neuropathy pain at any of twenty -one health centers in the country, which are under the administration of Primary Health Care Corporation (PHCC).

The overall prevalence of diabetes mellitus among adult Qatari population is high $(16.7 \%)$ with diagnosed DM (10.7\%) and newly diagnosed DM is 5.9\%, (Bener A, et al, 2009).

\section{Sample design}

The sample for the current study will be from 4388 diabetic patients, they form the diabetic population in the six health centers, where the study is carried. More details about the criteria of selection, sample size, subsample size from selected sites and method of data collections are in the next chapter.

The names of health centers written in bold in table 1 above were the six randomly selected sites where from the data collected. Randomization of selecting health center was done by using an online Random Choice Generator.

\section{Sample size}

The following simple formula (Daniel, 1999) used to calculate the adequate sample size $\mathrm{n}=\mathrm{Z} 2 \mathrm{x} \mathrm{P}$ (1$\mathrm{P} / \mathrm{d} 2$ ).

Where $\mathrm{n}=$ sample size,

$\mathrm{d}=$ Absolute error or precision (in proportion of one; if $5 \%, \mathrm{~d}=0.05$.

$\mathrm{Z}=\mathrm{Z}$ statistic for a level of confidence $=1.96$ as $95 \%$ is considered confidence

level and 0.05 significance level.

$\mathrm{P}=$ expected prevalence or proportion of DPNP in Qatar =

The DPNP prevalence in Qatar is $\mathrm{P}=37.1 \%$ (S. JAMBART et al, April 2011)

Sample size $=\underline{1.96 \times 1.96 \times .0 .37(1-0.371)}=\underline{3.8416 \times 0371.0 .629}=$

$$
0.05 \times 0.050 .0025
$$

$=\underline{3.8416 \times 0.23359}=\underline{\underline{358.58}}$ patients 0.0025

Therefore, the sample size for the present study was 384 DPNP patients / participants. As the data collection through using a questionnaire, a non-response rate considered. The non-response rate for previous surveys conducted in Qatar has been relatively small, about 5\%-10\%, similar to the rate got in studies carried in countries with a similar level of development to Qatar (World Health Survey Qatar, 2006).

In this study the non-response rate of $20 \%$, assumed to the required sample size

Sample size $\mathrm{x}$ Nonresponse rate $=\underline{358.58 \times 20}=\underline{\underline{71.716}}=72$ patients

100

By adding this result of expected nonresponse rate to the calculated size sample size, the total targeted sample size reaches four hundred sixty one $430.31=(358.8+71.71)$ Multiply sample size 430.37 by 1.5 (design effect (deff) .In general, for a well-designed study, the design effect usually ranges from one to three. $430.37 \times 1.5=645.55=646$ patients. Therefore, the current study sample size is 646 patients.

This done in order reach the target 359 participants, which were the diabetic patients taking medications treatment to treat DPNP.

To allocate subsample per each of six-selected health centers, the total sample size broke down depending on diabetic (type1 and type 2) patients registries in the six-health centers, see table1.

The Following calculations was done to allocate subsample of diabetic patients (n) in each, health center multiplied by the total sample size 461 participants, and then divided by the total number of diabetic patients (4388) in all the six health centers. See below table2.

To find a subsample size from each health center, here below equation, used. 


$$
\text { Sub }- \text { sample }=\frac{\text { Number of diabetic patients in site } \mathrm{x} \text { Total Sample Size }}{\text { Total Number of Diabetic in all sites }}
$$

\section{Sampling technique}

Data collected from all the six selected health centers on face-to-face an interview to answer a modified structured Self- Assessment Questionnaire (SAT). This questionnaire clinically validated (Ingela Wiklund et al, 2013) among patients with post herpetic neuralgia.

All investigators received very- well and structured training; they became well informed about the study questionnaire and technique to carry out a face-to-face interview in the proposed time for the interview. An investigator after getting a generic consent form a participant, then an interview ran for 20 to 30 minutes.

Participants were nonprobability selected .Participants were attending on their normal manner to visit the selected primary health centers during the data collection duration. The participants were receiving medication(s) for the treatment of DPNP, at the time of the data collection.

\section{Procedure of data collection}

All interviews were face - to -face interview. Investigators and / or data collectors got a participant's consent form before starting the interview. The SAT bilingual modified questionnaire used in all the six data collection sites. All data collected in a paper -based questionnaires.

The data collected from an eligible participant who coped with required inclusion criteria; patient on DPNP medications treatments for at least three to thirteen weeks, age from 18 years and above, no communication barriers. Patients would like to participate and they used same the medications for other medical conditions, for example, patients were using anticonvulsants medications for epilepsy, patients have mental disorders or psychic problems and were using anti-depressant medications, which can be used to relief DPNP.

Most interviews took from 20 to 30 minutes. Investigator / data collectors took a very high care not to influence the respondents' answers. The interviews carried not to affect patients - flow, and the interviews within the health center during the working hours for and in an office, pharmacy-counselling room. Only one questionnaire used for one participant and the participant chose by ticking one answer from the five given answers per each question. The participant had full freedom to answer the questionnaire rather than to carry an interview with investigator or data collector.

Six hundred forty six, 646, modified SAT questionnaires used to collect data from all the six data sites collection to reach the sample for this current study.

\section{Data analysis}

After conducting, the sampling procedure designated above. The actual sample size was 511 participants from all the six sites. Therefore, the overall response rate achieved was $79.1 \% .=\{511 \mathrm{x}$ 100)/646\}. Before the analysis done, the 511 collected data were and any uncompleted answered questionnaire removed from the analysis. The uncompleted ones found to be 167 i.e. only 344 -answered questionnaire and valid for analysis.

Therefore, only data collected from 344 respondents had been completed and entered into a spreadsheet for analysis. Data analyzed to test frequency and Chi-square test using Statistical Package for the Social Sciences (SPSS), version (IBM SPSS Statistics 24). Statistical significance is determined to have $p$-value of 0.05 and $95 \%$ is considered for confidence level.

The analysis conducted for this study was simple tabulations of the data against the important and studied subcategories. These categories were, in general, sex,, DPNP severity, duration of treatment, patients 'perceptions on medications benefits, nature and status of the work, nationality Qatari, and nonQatari composed of all other nationalities of the expatriates in Qatar. 


\section{Results}

The graph 1 below shows some clinical characteristics of the participants. Three hundred and forty four participants disclosed information describing their DPNP assessment before starting taking medications, which expected to be before the time of collecting data. Data collected on answering the question of; how the participants would expresses their DPNP before taking medications? To answer this question, the participants given, a scale from $0=$ (no pain), $5=$ (moderate pain) to $10=$ (worst pain).

One more question asked a participant, for how long he or she has taken medication(s) for treating DPNP in the time of collecting the data.

Depending on the participants' perceptions on their DPNP they experienced, they accordingly put into three groups. The first group resembles participants who experienced mild DPNP. The second group those who experienced moderate DPNP, and the third group they experienced severe DPNP.

Results obtained put in the see graph 1, which revealed that the first group, experienced mild DPNP formed about $9.9 \%(34 / 344)$ of the total participants. Those who described or assessed their DPNP as moderate pain, second group, formed a percentage of $40.1 \%$ (138/344). The third group represented by participants who experienced severe DPNP and they formed a 50\% (172/344) from the total participants.

The third group was 50\%, those who experienced severe DPNP reflected the importance of diabetes complications occurrence and necessity of addressing the treatment of these diabetic complication.

The current study contained mainly four durations for using DPNP medications, and accordingly the participants grouped. A participant had to choose one of these groups, to indicate for how long he or she has taken the DPNP medications. The given treatments durations covered both acute and chronic DPNP.

First group took the DPNP medications for durations of less than three weeks, when they accepted to take an interview as participants in this study. Second group, they took the medication for more than three weeks but for less than three months. The third group took DPNP medications for more than three months but for less than twelve months at the time of collecting data. Forth group took DPNP medications for more than twelve months at the time of collecting data.

In addition, graph 1 below shows the durations of taking the DPNP by the participants. The first group represented by $3.5 \%$ (12/344), they took medications for a duration started from zero time when a participant sensed DPNP up to three weeks, and medications taken. The second group formed $24.1 \%$ ( 83/344) of the participants took the DPNP medications for a duration of more than three weeks but less than three months. The third participants group formed $40.7 \%(140 / 344)$ they took DNPN medications for more than three months, but less than one year, i.e. for less than twelve consecutive months. The fourth participants group formed $31.7 \%(109 / 344)$ they took medication(s) to treat DPNP for more than one year, i.e. for more than twelve successive months.

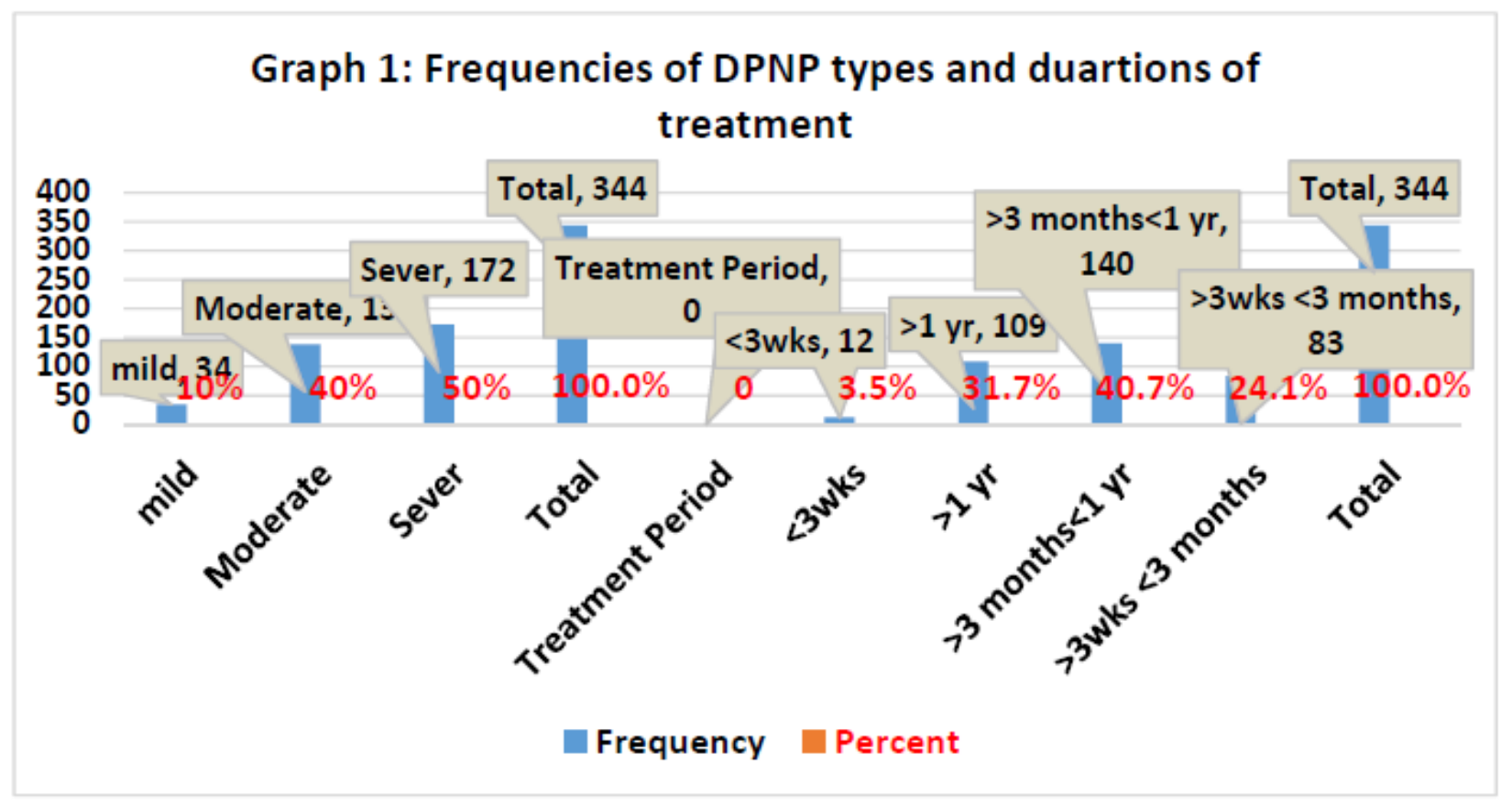


DOI: $10.21522 /$ TIJCR.2014.04.02.Art002

ISSN: $2520-3096$

Table 1. DPNP participant's information

\begin{tabular}{|l|l|l|}
\hline Characteristic & Frequency & Percentage \% \\
\hline Nationality & & \\
\hline Non- Qatari & 270 & $78.50 \%$ \\
\hline Qatari & 74 & $21.50 \%$ \\
\hline Gender & & \\
\hline Female & 120 & $34.90 \%$ \\
\hline Male & 224 & $65.10 \%$ \\
\hline Age in years & & \\
\hline $18-30$ & 7 & $2.00 \%$ \\
\hline $31-50$ & 116 & $33.70 \%$ \\
\hline $51-66$ & 166 & $48.30 \%$ \\
\hline$>66$ & 55 & $16.00 \%$ \\
\hline Work status & & \\
\hline Employee & 180 & $53.50 \%$ \\
\hline No-work & 137 & $38.70 \%$ \\
\hline Retired & 27 & $7.80 \%$ \\
\hline Work nature & & \\
\hline Labor & 49 & $27.22 \%$ \\
\hline Office & 131 & $72.78 \%$ \\
\hline Total & 180 & $100 \%$ \\
\hline
\end{tabular}

Table 2. Frequencies of uses of medications by 344 participants

\begin{tabular}{|l|l|l|}
\hline Medication & Frequency & Percentage \% \\
\hline Amitriptyline 10 mg & & 82.33 \\
\hline Carbamazepine 200 mg & 12 & 3.49 \\
\hline Celecoxib 200 mg & 3 & 0.87 \\
\hline Diclofenac 50 mg & & 10.29 \\
\hline Duloxetine $60 \mathrm{mg}$ & 83 & 24.13 \\
\hline Fluoxetine $20 \mathrm{mg}$ & 1 & 0.29 \\
\hline Gabapentin $300 \mathrm{mg}$ & 157 & 45.64 \\
\hline Imipramine $10 \mathrm{mg}$ & 5 & 1.45 \\
\hline Meloxicam $15 \mathrm{mg}$ & 5 & 1.45 \\
\hline Paracetamol 1000mg & 3 & 0.87 \\
\hline Pregabalin $150 \mathrm{mg}$ & 22 & 6.4 \\
\hline Pregabalin 75 mg & 43 & 12.5 \\
\hline Tenoxicam $20 \mathrm{mg}$ & 1 & 0.29 \\
\hline Total & $\mathbf{3 4 4}$ & $\mathbf{1 0 0 \%}$ \\
\hline
\end{tabular}

Table 2 above gives frequencies and percentages of medications used to treat 344 DPNP participants during the study from 30, April 2015 to 30, April 2016.

It found that gabapentin $300 \mathrm{mg}$ capsule without any combination with other DPNP medications used by $45.64 \%$ ( 157 / 344) participants at the .Then followed by duloxetine $60 \mathrm{mg}$ capsule used by $24.13 \%$ (83 / 344) participants, without any combination with another DPNP medication. Pregabalin $75 \mathrm{mg}$ capsule without any combination with another DPNP medication, was used by only $12.5 \%(43 / 344)$ participants. But pregabalin $150 \mathrm{mg}$ capsule, without any combination with another DPNP medication, found to be used only by $22 / 344$ participants at the rate of $6.4 \%$. On the other hand, all the other DPNP medications included in this study, they used at rates of $0.29 \%(1 / 344)$ to $3.49 \%(12 / 344)$ of participants.

The Chi - tests on version IBM SPSS Statistics 24 performed to find comparative analytic results for gender (120 females and 244 males) against the main five questions in the modified SAT questionnaire.

Table 2 shows the frequencies of uses of medications by 344 participants. Gabapentin $300 \mathrm{mg}$ used by 157 participants, it was the highest medication used in the current study, followed by duloxetine 30 
mg, pregabalin $75 \mathrm{mg}$, used by 43, pregablin $150 \mathrm{mg}$ used by 22 and carbamazepine $200 \mathrm{mg}$ used by 12 participants. The other medications included in the study used by less than 10 participants.

Table 3 is established to put together all the percentages of the 344 participants' perceptions on the benefits of the medications used in the current study for treating and relieving the diabetic peripheral neuropathy. The participants expressed their assessment by answering five questions to elucidate the DPNP consequences; like acuity of the pain, impacts on quality of life, influences on daily activity, if the participant would undergo the same medication treatment in the future. In addition to that to perceive which medication(s) alleged by at least by $50 \%$ of the participants to relieve the DPNP.

\section{Discussion}

This study is a cross section study. It targeted to detect the ability of diabetic patient in Qatar, can perceive the benefits of the medications they used for treating diabetic peripheral neuropathy pain (DPNP).

The study ran in six health centers out of twenty- one health center in under the management of Primary Health Care Corporation (PHCC) in Qatar. These six health centers selected randomly to represent whole State of Qatar.

The non-response rate for previous surveys conducted in Qatar was relatively small, about 5\%-10\%, (World Health Survey Qatar, 2006).In this study the nonresponse rate found to be $20 \%$. The sample size for the present study was 646 participants with DPNP.

After conducting, the sampling procedure designated above. The actual sample size was 511 participants from all the six sites. Therefore, the overall response rate achieved was $79.1 \% .=\{511 \mathrm{x}$ $100) / 646\}$.

Before the analysis done, the 511 collected data cleared by removal of incomplete answered questionnaires. Only 344 fully answered questionnaires analyzed.

Table 1 explicates frequencies and percentages of DPNP participants information non-Qatari expatriates formed the higher percent of the diabetic participants experienced DPNP than Qatari participants .So, expatriates experienced the most harmful of diabetes complications, peripheral neuropathy more than the Qatari diabetic patients . This occurred at the ratio of 270:74 (3.65:1) nonQataris: Qatari respectively. It is almost every four non-Qataris diabetic patients experience DPNP opposite to one Qatari. Although failure to keep blood sugar levels as close to normal cause developing DPND, other socio-economically factors, and being away from the mother home may play role inn aggravation of the complication of diabetes like DPNP.

Depending on the ages, the participants divided into four groups of age. Results of the current study revealed that the $33.7 \%$ (116/344) participants in the group of 51-65 years old, and 48.3\% (166/344) in the group of age 31- 50 of the participants suffered from DPNP. Collectively the participants at the ages from 31 to 50 years are the mostly workers and employees and productive. This may have direct influences on private and / or the general economic productivity as well as other fields of commerce and lastly the national economy. Therefore the DPNP has impact on diabetics and their productivity and, hence quality of life and daily activity.

From the results, it noted that the employees53.5\% (180/344) suffered from DPNP more than those who do not have work38.7\%( 137/344) or retired $7.8 \%$ (27/344).

Amongst the employees who suffered DPNP, who works at offices72.78 \%( 131/344) were more than labors $27.22 \%$ ( 49/344) with DPNP. Because the DPNP is, a major complication of uncontrolled diabetes .These results may give signals of that employees who work at offices were less controlling blood sugar, or because of sedentary, or limited movements and low activity in comparison to the labors.

Graph 1 shows grouping of the participants according to the acuity of the DPNP. Halve of the participant's 172/344 experienced severe DPNP, followed by $40 \%$ of the participants experienced moderate DPNP. Only $10 \%$ of the participants suffered mild DPNP. These result may give indication of poor glucose blood control, and this settle with studies that related severity of DPNP with poor glycemic control. The beneficial effect of successful glycemic control on painful symptoms is limited to small studies (Aristides Veves, Miroslav Backonja, Rayaz A. Malik, and 30- July 2007). 'Improvement in controlling blood glucose with insulin has improved harshness of symptoms (Christopher H Gibbons, Roy Freeman, and April 2010)'. 
In addition, graph 1 shows frequencies and percent of durations through which the participants used DPNP medications. Mostly The participants used the DPNP medications for long duration, from three weeks up to more than twelve months. The durations reflected the nature of DPNP and its chronicity has an impact on patients' quality of life and their daily activity. One hundred - forty participants (40.7\%) used DPNP medications for more than three months and less than twelve months. Hundred - nine $(31.7 \%)$ of the participants used DPNP medications for more than 12 months. Eighty-three $(24.1 \%)$ of the participants used DPNP medications for duration of more than 3 weeks and less than 3 months. Only twelve (3.5\%) participants used DPNP medications for less than 3 weeks for treating DPNP. In human fear in particular appears to play a central role in the duration of pain, catastrophizing thoughts lead to pain related fear' (McCracken LM, Gross RT, Dec.1993), (Vlaeyen JW, Kole-Snijders AM, Boeren RG, van Eek H. 1995).

It can be summarized from the graph 1 most of diabetic patients experienced DPNP and used medication for long duration. But it is not only uncontrolled blood sugar is causes of experiencing severe DPNP and necessitates longer duration of treatment, other factors of fear, depression and anxiety may also be indicators for central nervous system physiology that play a substantial role in the durability of pain (Katona C, Peveler R, Dowrick C, et al. 2005).

The results revealed by the current study regarding the durations for treating DPNP, exactly the durations of three months to twelve months, and a duration of more than twelve months, lie within the range of $30 \%$ to $65 \%$ (Katona C, Peveler R, Dowrick C, et al. 2005).

Table3 established to put all together the percentages of the 344 participants' perceptions on the benefits of the medications for treating and relieving DPNP. Participants' perceptions on the beneficial of DPNP medications covered the beneficial on the following; relieving of diabetic peripheral neuropathy accompanied consequences like pain, impacts on quality of life, influences on daily activity, if the participant would undergo the same medication treatment in the future.

The participant's perceptions averages on the benefits of the DPNP medications, collected after the answering the five questions in the questionnaire used for the present study. All these averages for each medication added together and then divided by five to get the average of benefits that participants' perceived in all the five questions for that medication.

All the participants' perceptions on each medication collected from the five answered questions added together, then divided by five to get the average of benefits for each DPNP medication. Medications having same generic name and different strength considered as different medications as the dose difference has different efficacy. See the last right column in the table 3.

The findings averages percentages of participants' perceptions more than $50 \%$ on the benefits of the DPNP medications to relieve the DPNP pain, they arranged here from highest percentage to the lowest one: $80 \%$ diclofenac, $70.70 \%$ gabapentin $300 \mathrm{mg}, 68.33 \%$ carbamazepine $200 \mathrm{mg}, 57.5 \%$ amitriptyline 10mg, $54.89 \%$ pregabalin $75 \mathrm{mg}, 50.84 \%$ duloxetine $60 \mathrm{mg}$.

The following averages percentages of participants' perceptions less than $50 \%$ on the benefits of the medications used for treating DPNP, arranged here from highest percent to the lowest one $; 46.67 \%$ celecoxib 200mg, 44.55\% pregabalin $150 \mathrm{mg}$, 40\%tenoxicam $20 \mathrm{mg}, 32 \%$ meloxicam $15 \mathrm{mg} 26.67 \%$ paracetamol $1000 \mathrm{mg}, 24 \%$ imipramine $10 \mathrm{mg}, 0 \%$ fluoxetine $20 \mathrm{mg}$. 
동

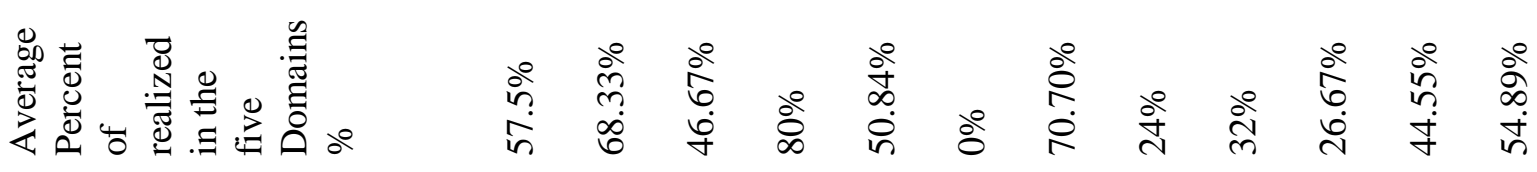

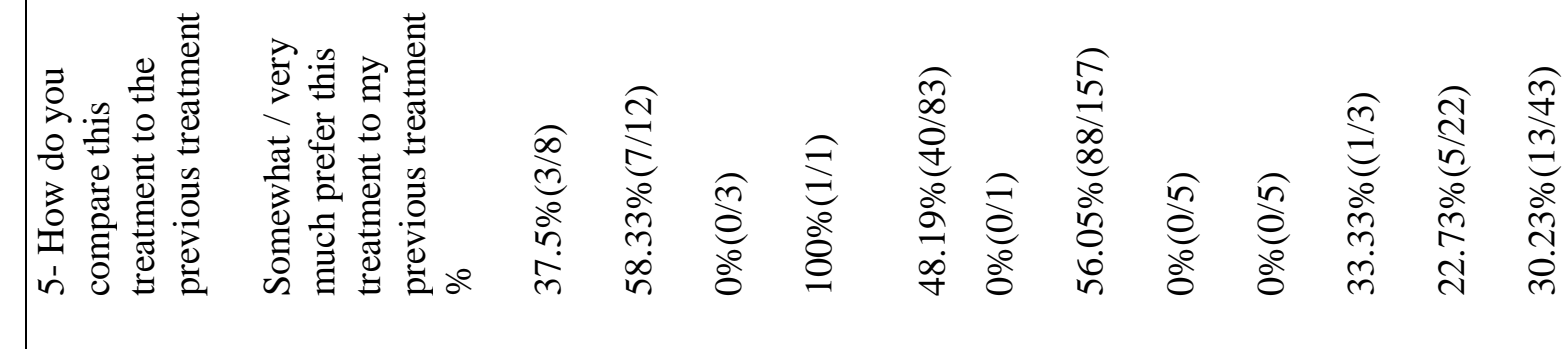

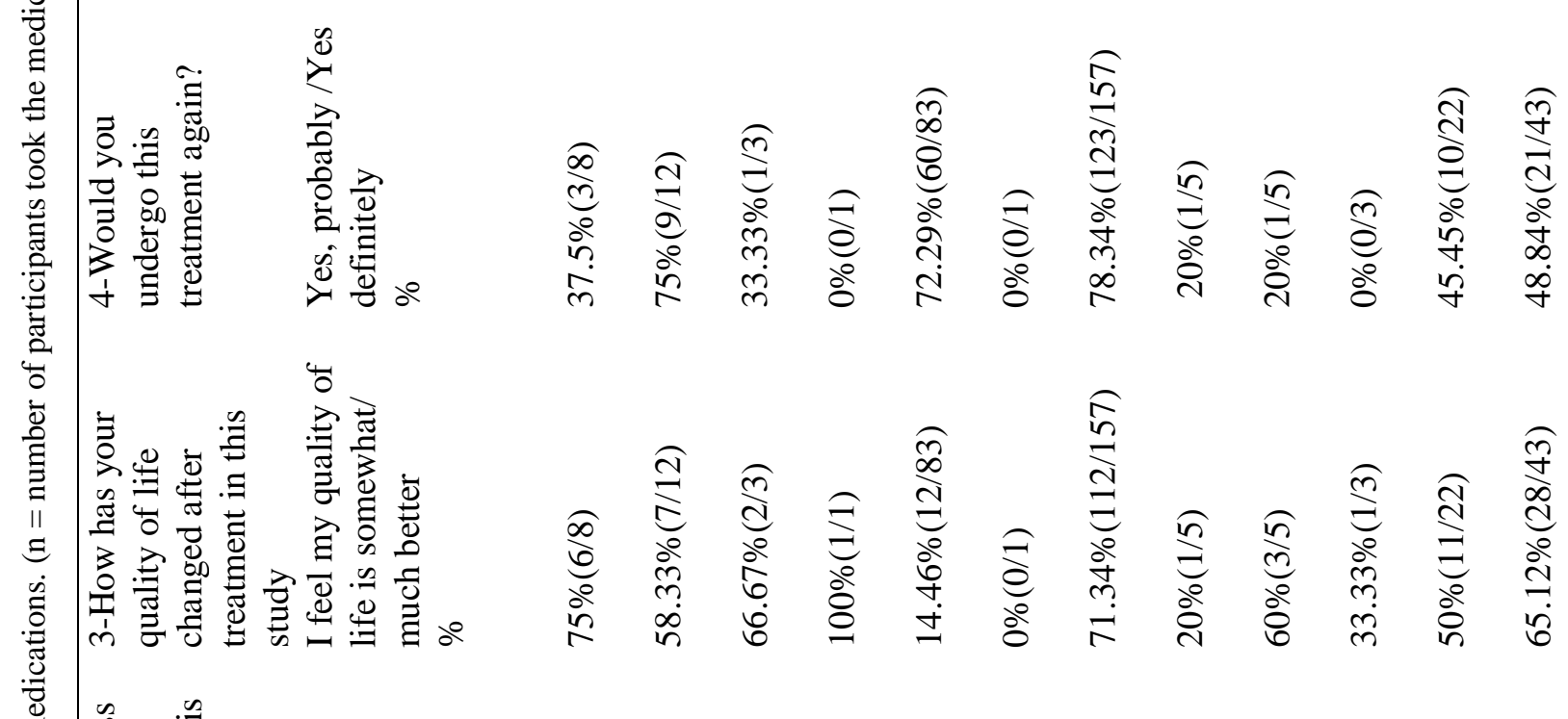

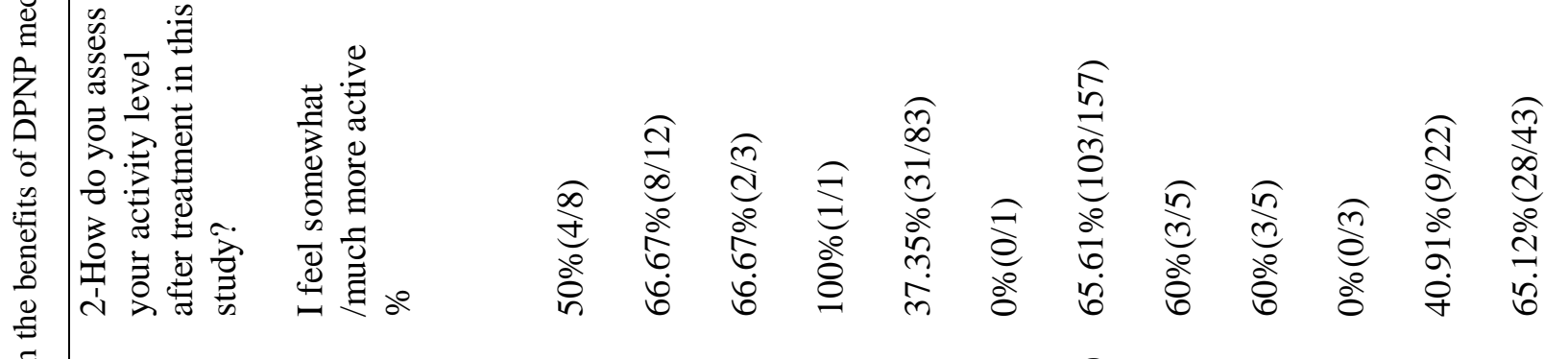

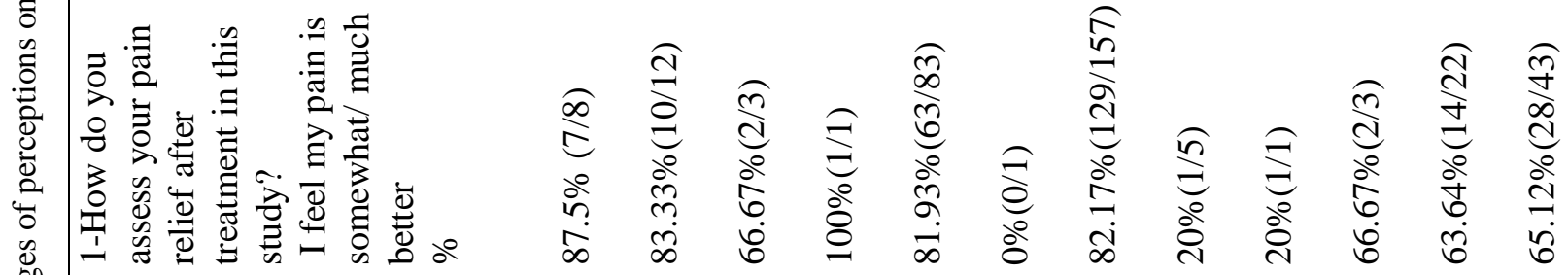
要

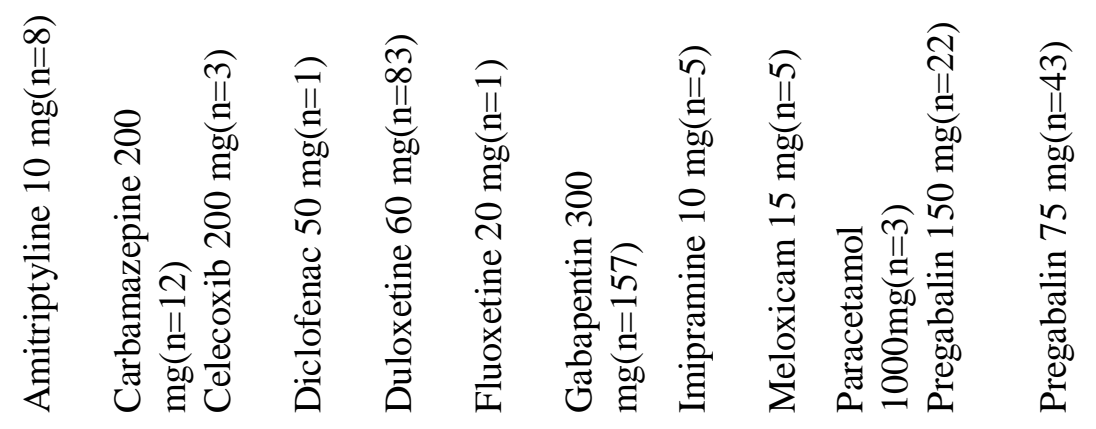




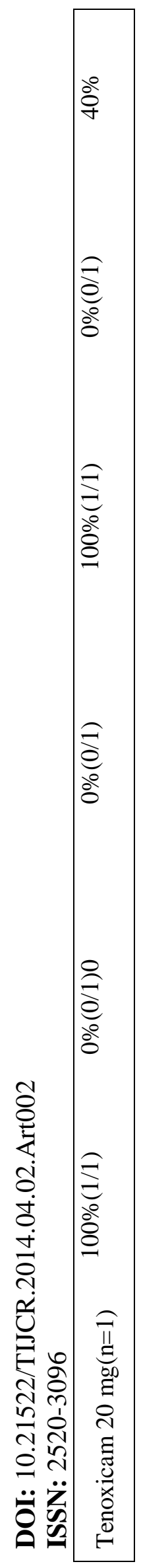


The higher percentage of perceptions on the benefits for treating DPNP above $50 \%$, reported by one participant, who took diclofenac $50 \mathrm{mg}$. This result for diclofenac $50 \mathrm{mg}$ couldn't be considered and clinically was insignificantly as it was used by one participant.

Gabapentin $300 \mathrm{mg}$ perceived by the average of $70.70 \%$ to be beneficial to relieve the DPNP. So gabapentin $300 \mathrm{mg}$, whatever the dose and frequency in the current study, was the highest medication that realized more than 50\% in releasing DPNP in comparison to the medications included in this study.

It is also noted that other anticonvulsants; carbamezapine $200 \mathrm{mg}$, pregablin $75 \mathrm{mg}$ realized more than $50 \%$ to be beneficial in DPNP. Pregabalin $150 \mathrm{mg}$, it was exception, as it found to be perceived by less than $50 \%$ to be beneficial in DPNP.

Duloxetine $30 \mathrm{mg}$, an antidepressant used in this study realized percentage more than $50 \%$ beneficial to the participants. But Imipramine $10 \mathrm{mg}$ compared perceived by less than $50 \%$ to be beneficial in treating DPNP. Fluoxetine $20 \mathrm{mg}$ used by on participant, and it failed completely to be perceived as beneficial for treating DPNP.

All the nonsteroidal anti-inflammatory drugs; celecoxib 200mg mg, tenoxicam $20 \mathrm{mg}$, meloxicam $15 \mathrm{mg}$ and paracetamol $1000 \mathrm{mg}$ in the present study perceived to be less than $50 \%$ beneficial to the participants. The only exception was diclofenac $50 \mathrm{mg}$, see above.

\section{List of Abbreviations}

\begin{tabular}{|c|c|}
\hline AIDS & $\begin{array}{l}\text { Acquired Immune deficiency } \\
\text { Disease }\end{array}$ \\
\hline AND & Autonomic Diabetic Neuropathy \\
\hline Anti-TNF & Anti- Tumor Necrosis Factor \\
\hline $\mathrm{AOD}$ & Action on Diabetes \\
\hline CRPS & Complex Regional Pain Syndrome \\
\hline DFDs & diabetic foot disorders \\
\hline DPN & Diabetic Peripheral Neuropathy \\
\hline FDN & Focal Diabetic Neuropathy \\
\hline GCC & Gulf Cooperation Council \\
\hline $\mathrm{HGH}$ & Hamad General Hospital \\
\hline HIV & Human Immunodeficiency Virus \\
\hline HMRC & Hamad Medical Research Center \\
\hline IASP & $\begin{array}{l}\text { International Association for the } \\
\text { Study of Pain }\end{array}$ \\
\hline I. V & Intravenous \\
\hline LANSS & $\begin{array}{l}\text { Leeds Assessment of Neuropathic } \\
\text { Symptoms and Signs Pain Scale }\end{array}$ \\
\hline $\mathrm{NP}$ & Neuropathic pain \\
\hline NSAIDs & Non-steroidal Anti- Inflammatory \\
\hline SAT & self-assessment treatment \\
\hline PASW & $\begin{array}{l}\text { Predictive Analytics Software } \\
\text { (applied statistical software) }\end{array}$ \\
\hline PBS & Pharmaceutical Benefits Scheme \\
\hline
\end{tabular}

\section{References}

[1]. Abbas Al Jalabi, AE. Ayad, N. Ghaly, R. Ragab, S. Majeed, H. Nassar, A. AL Shoaibi, S. EL Noor, A. Salti, J. Costandi, AZ. Zeidan, SA. Schug. journal of international medical (August 2011). Journal of International Medical

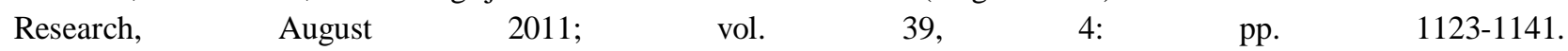
http://imr.sagepub.com/search?author $1=\mathrm{AE}+$ Ayad\&sortspec=date\&submit=Submit

[2]. Aristidis Veves, Miroslav Backonja, Rayaz A. Malik, and (30- July 2007) Painful Diabetic Neuropathy: Epidemiology, Natural History, Early Diagnosis, and Treatment Options .American Academy of Pain Medicine 15262375/08/\$15.00/660 660-674 doi:10.1111/j.1526-4637.2007.00347.

[3]. Barrett AM Lucero MA, Le T, Robinson RL, Dworkin RH, Chappell AS, 2007. Epidemiology, public health burden, and treatment of diabetic peripheral neuropathic pain: a review. Pain Med. 2007; 8(suppl 2):S50-S62.

[4]. Bener A, Zirie M, Janahi IM, Al-Hamaq AO, Musallam M, Wareham NJ(2009). Prevalence of diagnosed and undiagnosed diabetes mellitus and its risk factors in a population-based study of Qatar. Diabetes Res Clin Pract, 2009 Apr; 84(1):99-106. doi: 10.1016/j.diabres.2009.02.003. 
DOI: 10.21522/TIJCR.2014.04.02.Art002

ISSN: 2520-3096

[5]. Bonnie Sanders Polin .How to Treat Diabetic Neuropathy. Diabetic Nerve Pain: A Diabetes Complication. http://www.diabeticlifestyle.com/relatedconditions/neuropathy/how-treat-diabetic-neuropathy

http://www.diabeticlifestyle.com/related-conditions/neuropathy/how-treat-diabetic-neuropathy .First published on June 1, 2002.Updated on: May 12, 2016.

[6]. Christopher H Gibbons, Roy Freeman, April 2010 .Treatment induced diabetic neuropathy- a reversible painful autonomic neuropathy. NIH Public Access- Arthur Manuscript. Ann Neurol. 2010 April; 67(4): 534-541. doi:10.1002/ana.21952.

[7]. Davies M, et al. Diabetes Care. 2006; 29: 1518-22. https://public.lillydiabetes.co.uk/diabetes/living-withdiabetes/diabetes

[8]. Daniel WW (1999). Biostatistics: A Foundation for Analysis in the Health Sciences. Seventh edition. New York: John Wiley \& Sons.

[9]. Erah* and NA Chuks-Eboka, 2008).Patients' Perception of the Benefits of Pharmaceutical Care Services in the Management of Hypertension in a Tertiary Health Care Facility in Benin City Pharmacotherapy Group, Faculty of Pharmacy, University of Benin. http://www.tjpr.org.

[10]. Gelman, H. Stern. The Difference Between "Significant" and "Not Significant" is not Itself Statistically Significant. The American Statistician, 60:328-331, 2006.

[11]. Galer BS, et al. Painful diabetic polyneuropathy: epidemiology, pain description, and quality of life.2000. https://www.ncbi.nlm.nih.gov/pubmed/10670912

[12]. Gene Shackman, 2001, NYS DOH, Presented at Albany Chapter of American Statistical Association, March 24, $2001 \mathrm{http}: / /$ faculty.smu.edu/slstokes/stat6380/deff\%20doc.pdf.

[13]. Greg Bozimowski, CRNA, MS, 2012. Patient Perceptions of Pain Management Therapy. Pain Manag Nurs. 2012; 13(4):186-193. http://www.medscape.com/viewarticle/774955

[14]. Ingela Wiklund et al. Are treatment benefits in neuropathic pain reflected in the self-assessment of treatment questionnaire? Wiklund et al. Health and Quality of Life Outcomes 2013, 11:8. http://www.hqlo.com/content/11/1/8.

[15]. J. Robinson, Vladimir Skljarevski, a Sandra K; (Duloxetine, Pregabalin, and Duloxetine Plus Gabapentin for Diabetic Peripheral Neuropathic Pain Management in Patients With Inadequate Pain Response to Gabapentin: An Open-Label, Randomized, Noninferiority Comparison. Malcolm.Mayo Clin Proc. 2011 Jul; 86(7): 615-626. PMCID: PMC3127557 .doi: 10.4065/mcp.2010.0681.

[16]. Jaeschke R, Singer J, Guyatt GH, December, 1989. Measurement of health status: ascertaining the minimal clinically important difference. Control Clin Trials. 1989;10:407-15.[PubMed]

[17]. Journal of the American Geriatrics Society (1998; 46:635-651).WebMD Public Information from the U.S. National Institutes of Health Reviewed on September 29, 2006. http://www.webmd.com/pain-management/chronicpain-conditions?page $=2$

[18]. Katona C, Peveler R, Dowrick C, et al. Pain symptoms in depression: definition and clinical significance. Clin Med. 2005; 5:390-395. [PMC free article] [PubMed].

[19]. Kristen Jefferies Treatment of Neuropathic Pain Semin. Neurol. 2010; 30(4):425-432. http://www.medscape.com/viewarticle/730671_4

[20]. Lunn MP, Hughes RA, Wiffen PJ, 2014).Duloxetine for treating painful neuropathy, chronic pain or fibromyalgia. Cochrane Database Syst Rev. 2014 Jan 3; ( 1):CD007115. Doi: 10.1002/14651858.CD007115.pub3. Review.

[21]. Mark Davies, Sinead Brophy, Rhys Williams, and Ann Taylor, July 2006.The Prevalence, Severity, and Impact of Painful Diabetic Peripheral.

[22]. Mark Peyrot and Richard R Rubin, June 2011).Perceived medication benefits and their association with interest in using inhaled insulin in type 2 diabetes: a model of patients' cognitive framework. Doi: 10.2147/PPA.S18799.

[23]. McCracken LM, Gross RT, Dec.1993, Does anxiety affect coping with chronic pain? Clin J Pain. 1993 Dec; 9(4):253-9. PMID: 8118089.

[24]. McKillup, Steve (2006). "Probability helps you make a decision about your results". Statistics Explained: An Introductory Guide for Life Scientists (1st ed). Cambridge, United Kingdom: Cambridge University Press. pp. 44-56. ISBN 0-521-54316-9.

[25]. Milana Votrubec, Ian Thong,2013. Neuropathic pain a management update Volume 42, No.3, March 2013 Pages 92-97. http://www.racgp.org.au/afp/2013/march/neuropathic-pain-update/

[26]. -Minnesota Department of Human Services. http://www.dhs.state.mn.us/main/groups/county_access/documents/pub/dhs16_180273.pdf .Last update: 06/04/2014.Neuropathy in Type 2 Diabetes. American Diabetes Association. doi.org/10.2337/dc05-2228. 
[27]. Mitchell B. Max, Sue A. Lynch,, Joanne Muir, R.N, Susan E. Shoaf,, Bruce Smoller,, Ronald Dubner: Effects of Desipramine, Amitriptyline, and Fluoxetine on Pain in Diabetic Neuropathy N Engl J Med 1992; 326:1250-1256May 7, 1992DOI: 10.1056/NEJM199205073261904.

[28]. Palmer RH. Considerations in defining quality of care. In Palmer RH (ed.). Striving for Quality in Health Care: An Inquiry into Policy and Practice. Ann Arbor: Health Administration .Press 1991:1-59.

[29]. Pam Harrison November 13, 2014: No Clear Winner for Relief of Diabetic Neuropathy Pain- Medscape Medical News. http://www.medscape.com/viewarticle/834877\#vp_2

[30]. Qatar Population. Trading and Economics. http://www.tradingeconomics.com/qatar/population-

[31]. Random Choice Generator .www.textfixer.com/tools/random-choice.php

[32]. Rayaz. Malik, Jan.2015, Grand Rounds explores novel diagnostic test for diabetic neuropathy Weill Cornell Medical College in Qatar. http://qatar-weill.cornell.edu/media/reports/2014/diagnostic-test-for-diabeticneuropathy.html.

[33]. Robert H. Dworkin et al 2007, Pharmacologic management of neuropathic pain: Evidence-based recommendations. Pain 132 (2007) 237-251. www.elsevier.com/locate/pain

[34]. Robert J. Tanenberg, Gordon A. IrvingRichard C. Risser; Jonna Ahl, Michael

[35]. Theesen KA, Marsh WR. Relief of diabetic neuropathy with fluoxetine. DICP.1989 Jul-Aug; 23(7-8):572-4. PubMed PMID: 2788334. https://www.ncbi.nlm.nih.gov/pubmed/2788334

[36]. Theresa M. Wizemann and Mary-Lou Pardue, 2001, Does Sex Matter? Committee on Understanding the Biology of Sex and Gender Differences; Board on Health Sciences Policy; Institute of Medicine. DOI: $10.17226 / 10028$.

[37]. Vlaeyen JW, Kole-Snijders AM, Boeren RG, van Eek H. Fear of movement/(re)injury in chronic low back pain and its relation to behavioral performance. Pain. 1995; 62:363-372. [PubMed.

[38]. WebMD Medical Reference from Healthwise. Pain Medicines for Diabetic Neuropathy-Topic Overview http://www.webmd.com/diabetes/tc/pain-medicines-for-diabetic-neuropathy-topic-overview last Updated: June 04, 2014.

[39]. William C. Shiel, Jr 2014. Pain (Chronic and Acute) - Medicine Net http://www.medicinenet.com/script/main/art.asp?articlekey=40842

[40]. William H. Shrank, Emily R. Cox, Michael A. Fischer, Jyotsna Mehta, and Niteesh K. Choudhry, 2009. Patients' Perceptions of Generic Medications: doi:10.1377/hlthaff.28.2.546.

[41]. World Health Survey Qatar,2006 http://www.biomedcentral.com/content/supplementary/1478-7954-12-18S1.pdf 